\title{
Solid State Properties of Poly(spiro[2,4]hepta-4,6-diene)
}

\author{
Hiroaki Sugimoto, ${ }^{*}$ Motowo Takayanagi, and Toyoki Kunitake** \\ Department of Applied Chemistry, Faculty of Engineering, \\ Kyushu University, Fukuoka 812, Japan.
}

(Received October 6, 1976)

\begin{abstract}
Poly(spiro[2,4]hepta-4,6-diene) (PSHD) is considered to behave like a rigid rod on the basis of the unusually large index $(\alpha=1.7)$ in the viscosity-molecular weight relationship. Thus, some solid state properties were investigated with PSHD samples which contained different ratios of the 1,2- and 1,4-addition units. The thermo-mechanical curve of solvent-cast films showed that there were two $\tan \delta$ peaks below $300^{\circ} \mathrm{C}$. The $\beta$ peak was located at about $130^{\circ} \mathrm{C}(110 \mathrm{~Hz})$, and affected little by the polymer composition. On the other hand, the position of the $\alpha$ peak shifted linearly from $200^{\circ} \mathrm{C}$ to $300^{\circ} \mathrm{C}$ with increasing fraction of the 1,4-unit, and the peak height decreased simultaneously. A loss peak associated with thermal decomposition and/or crosslinking was found at temperatures above $300^{\circ} \mathrm{C}$. The TGA curve revealed that the thermal decomposition of PSHD takes place at about $300^{\circ} \mathrm{C}$ in air and at about $400^{\circ} \mathrm{C}$ under nitrogen. An exothermic peak was found in the same temperature range in the DSC curve. The crosslinked specimen showed no loss peak in dynamic measurements, which reflected immobilization of the molecule by crosslinks. The PSHD film did not show any indication of crystallinity.

KEY WORDS Poly(spiro[2,4]hepta-4,6-diene) / Rigid Polymer / Thermogravimetric Analysis / Thermomechanical Analysis / Viscoelastic Property /
\end{abstract}

One of the authors has reported that spiro$[2,4]$ hepta-4,6-diene, a one-step derivative of cyclopentadiene, undergoes facile polymerization with a variety of cationic initiators. ${ }^{1,2}$ The polymer consisted of the 1,2- and 1,4-addition structures, as inferred from spectroscopic evidence. The cyclopropyl ring did not open during the course of the cationic propagation, in contrast with radical copolymerization. ${ }^{3}$

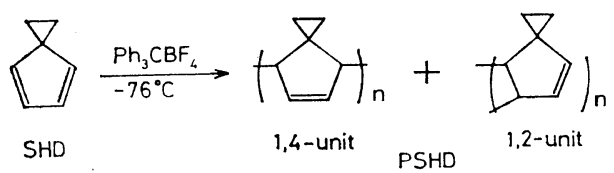

The content of the two structural units varied

* On leave from the Central Research Laboratory of Sumitomo Chemical Industries Co., Ltd.

** Department of Organic Synthesis, Kyushu University. characteristically with counteranions when triphenylmethyl salts were employed as initiator. ${ }^{2}$

The relation between intrinsic viscosity and number-average molecular weight is represented by eq 2 .

$$
[\eta]_{\text {toluene }}^{30^{\circ}}=4.5 \times 10^{-8} \cdot \bar{M}_{n}{ }^{1.7}(\mathrm{~d} l / \mathrm{g})
$$

It is remarkable that the power index of $\bar{M}_{n}$ in the Mark-Houwink viscosity equation was 1.7, which is much greater than those of the usual flexible polymers with the random coil conformation. High index values such as this have been reported only for rodlike polymers like collagen and helical polypeptides. ${ }^{4}$ In fact, in the space-filling molecular model the spirocyclopropyl ring exerts large steric hindrance toward the conformational mobility.

In this paper, some solid state properties of this peculiar polymer are reported for the polymer samples of different structures. The effect of the polymer composition on the $\tan \delta$ peak in 
the thermo-mechanical analysis was studied, and thermally-resistant properties produced by the molecular stiffness were measured by the TGA and DSC methods.

\section{EXPERIMENTAL}

\section{Materials}

SHD was prepared by a modification of the published procedure. ${ }^{3}$ A typical procedure is as follows. In a $500 \mathrm{~m} l$ three-necked flask equipped with a mechanical stirrer, a thermometer, and a graduated dropping funnel were placed $198 \mathrm{~g}(2 \mathrm{~mol})$ of 1,2-dichloroethane, $320 \mathrm{~g}$ of 50 -wt $\%$ aqueous sodium hydroxide $(4 \mathrm{~mol})$, and $4 \mathrm{~g}$ of trioctylmethylammonium chloride (phase transfer catalyst). The mixture was stirred at temperatures below $10^{\circ} \mathrm{C}$, and cyclopentadiene $(160 \mathrm{~g}, 2.4 \mathrm{~mol})$ was added dropwise over $2 \mathrm{hr}$. Then the dropping funnel was replaced by a reflux condenser and the mixture was heated at about $60^{\circ} \mathrm{C}$ for $1 \mathrm{hr}$. The organic layer was separated and the aqueous layer extracted with ether. The combined organic layers were dried over anhydrous sodium sulfate overnight and distilled under reduced pressure. The synthetic yield of SHD was about $75 \%$, as estimated by gas chromatography. The distillate containing unreacted 1,2-dichloroethane was purified by repeated distillations: bp $65^{\circ} \mathrm{C}$ $(144 \mathrm{~mm})$ [lit. $\left.{ }^{5} 57^{\circ} \mathrm{C}(100 \mathrm{mmHg})\right]$. The purity of the final fraction was better than $99 \%$, as confirmed by gas chromatography.

Polymerization initiators and solvents, as listed in Table I, were prepared and/or purified by the previous methods. ${ }^{1,2}$

\section{Procedures}

The polymerization of SHD was carried out as follows. After flaming and cooling under reduced pressure, the polymerization flask was filled with dry nitrogen gas. Solvent and a catalyst solution were added through serum caps and the flask was cooled to about $-76^{\circ} \mathrm{C}$ in a dry ice-methanol bath. Then a monomer solution was slowly added with stirring. The polymerization was stopped by adding a pyridine solution, and the polymer was recovered by pouring the reaction mixture into methanol.

PSHD films were cast from benzene solution and kept under reduced pressure for a week.

\section{Instruments}

Gas chromatograms were obtained with a Shimadzu GC-3AH instrument: Silicone GE $\mathrm{SE} 31,70^{\circ} \mathrm{C}$, carrier gas $\mathrm{H}_{2}$. Infrared and NMR spectra were obtained by using Perkin-Elmer Model 337 and JEOL Model JNM-MH60 spectrometers, respectively. Thermomechanical measurements were carried out with a Rheovibron dynamic viscoelastometer Model DDV-IIB; the frequencies employed were $3.5,11$, and $110 \mathrm{~Hz}$. The heating rate was $1-2^{\circ} \mathrm{C} / \mathrm{min}$. Thermogravimetric analysis was carried out on a Cahn-RG-electrobalance, with a heating rate of $5^{\circ} \mathrm{C} / \mathrm{min}$. Differential scanning calorimetry was performed by a Rigaku Denki Thermoflex instrument. The heating rate was $5^{\circ} \mathrm{C} / \mathrm{min}$. $\mathrm{X}$-ray diffraction was obtained by a Rigaku Denki Rota Unit RU-3.

\section{RESULTS AND DISCUSSION}

\section{Polymerization}

Table I gives the polymerization results. The polymerization was fast in all cases. The polymers obtained were soluble in many solvents, such as chloroform, benzene, toluene, 1,2-di-

Table I. Polymerization of SHD at $-76^{\circ} \mathrm{C}$

\begin{tabular}{|c|c|c|c|c|c|c|c|c|}
\hline No. & $\begin{array}{l}\text { Initiator, } \\
\mathrm{mmol} / l\end{array}$ & & $\underset{\mathrm{mon} / \mathrm{l}}{\mathrm{Momer}}$ & Solvent & $\begin{array}{l}\text { Time, } \\
\text { min }\end{array}$ & $\begin{array}{c}\text { Con- } \\
\text { version, } \\
\%\end{array}$ & $\begin{array}{l}{[\eta]_{\text {toluene }}^{30^{\circ}}} \\
\quad \mathrm{d} l / \mathrm{g}\end{array}$ & $\begin{array}{l}\text { 1,4-unit } \\
\text { in polymer } \\
\%\end{array}$ \\
\hline 1 & $\mathrm{BF}_{2} \mathrm{O}\left(\mathrm{C}_{2} \mathrm{H}_{5}\right)_{2}$ & 3.0 & 0.25 & $\mathrm{CH}_{2} \mathrm{Cl}_{2}$ & 15 & 90 & 1.2 & 42 \\
\hline 2 & $\mathrm{SnCl}_{4}-\mathrm{TCA}^{\mathrm{a}}$ & 0.25 & 0.25 & $\mathrm{CH}_{2} \mathrm{Cl}_{2}$ & 10 & 90 & 3.0 & 38 \\
\hline 3 & $\left(\mathrm{C}_{6} \mathrm{H}_{5}\right)_{3} \mathrm{C}^{+} \mathrm{BF}_{4}-$ & 0.45 & 0.45 & $\mathrm{CH}_{2} \mathrm{Cl}_{2}$ & 180 & 95 & 4.0 & 47 \\
\hline 4 & $\left(\mathrm{C}_{6} \mathrm{H}_{5}\right)_{3} \mathrm{C}^{+} \mathrm{BF}_{4}^{-}$ & 0.13 & 0.30 & $\begin{array}{c}\mathrm{CH}_{2} \mathrm{Cl}_{2}-\text { toluene } \\
(1: 1)\end{array}$ & 10 & 90 & 4.8 & 70 \\
\hline 5 & $\left(\mathrm{C}_{6} \mathrm{H}_{5}\right)_{3} \mathrm{C}^{+} \mathrm{BF}_{4}^{-}$ & 0.07 & 0.32 & $\begin{array}{c}\mathrm{CH}_{2} \mathrm{Cl}_{2}-\text { toluene } \\
(3: 7)\end{array}$ & 10 & 92 & 4.4 & 84 \\
\hline
\end{tabular}

a Trichloroacetic acid. 
chloroethane, tetrachloroethylene, and carbon tetrachloride, and were white powders of fibrous materials. Intrinsic viscosities of 1.2 and $4.0 \mathrm{~d} l / \mathrm{g}$, for example, correspond to $\bar{M}_{n}=22,000$ and 47,000 , respectively, based on eq. 2 . The content of the 1,2- and 1,4-addition units was determined from the relative peak area of the olefin protons in NMR spectra, as described previously. ${ }^{2}$ It is clear that the polymer structure can be varied extensively by changing the polymerization conditions.

\section{$X$-Ray Diffraction}

The X-ray diffraction pattern of PSHD cast films (samples: No. 1, 3, and 5 in Table I) showed halos in the cases of both the perpendicular and parallel irradiation of the X-ray beam to the surface of a film. Neither orientation nor crystallinity was detected for the roll-extended PSHD (room temperature, by a factor of two) and for the sample uniaxially drawn $\left(220^{\circ} \mathrm{C}\right.$ in a silicone oil bath, by a factor of five). The PSHD molecule is composed of two different structures. Presumably, the 1,2-unit will prevent straightening of rigid segments composed of the 1,4-unit sequence. The probable existence of cis and trans linkages between the structural units makes the situation more complex. These irregularities must interfere with the crystallization of PHSD.

\section{Thermal Properties}

Differential scanning calorimetry (DSC) curves of the polymer (sample: Table I, No. 1) are shown in Figure 1. The curve obtained under nitrogen atmosphere showed a slight shift of the base line to the endothermic side (downward) at about $190^{\circ} \mathrm{C}$, while that in air (broken line) showed a deviation upward from the base line at the same temperature range. Consequently, the PSHD molecule appears to gain some molecular motions at temperatures above $190^{\circ} \mathrm{C}$. The exothermic peaks at $351^{\circ} \mathrm{C}$ under nitrogen and at $362^{\circ} \mathrm{C}$ in air might be due to the decomposition reaction and/or crosslinking.

Figure 2 shows thermogravimetric analysis (TGA) curves under nitrogen gas (solid line) and in air (broken line). The oxidation of the polymer seems to take place at about $150^{\circ} \mathrm{C}$, as reflected by a slight increase in the sample weight. The $\nu_{\mathrm{C}=0}$ band $\left(1,700 \mathrm{~cm}^{-1}\right)$ and the

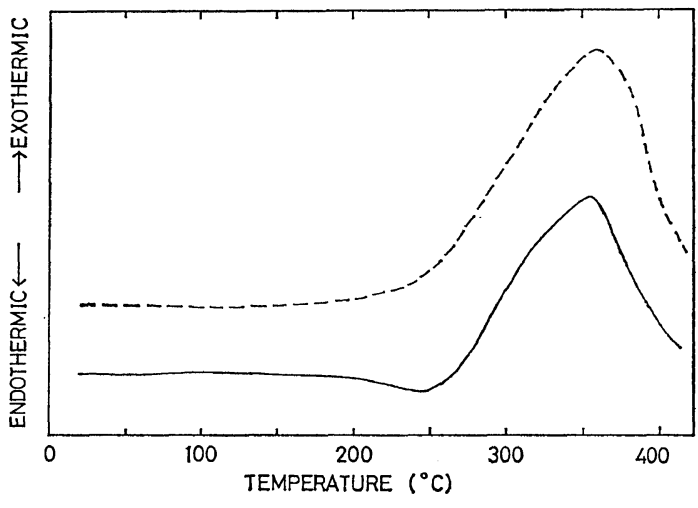

Figure 1. DSC curves of PSHD in $\mathrm{N}_{2}$ atmosphere (solid line) and in air (broken line): Sample, No. 1 in Table $\mathrm{I}$.

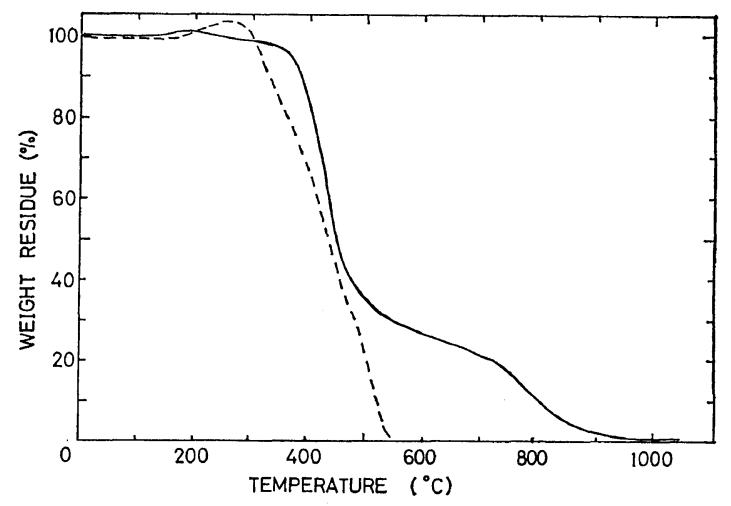

Figure 2. TGA curves of PSHD in $\mathrm{N}_{2}$ atmosphere (solid line) and in air (broken line): Sample, No. 1 in Table $\mathbf{I}$.

$\nu_{\mathrm{OH}}$ band $\left(3,580 \mathrm{~cm}^{-1}\right)$ were newly observed in IR spectra of the sample annealed at $200^{\circ} \mathrm{C}$. The decomposition was extensive above $300^{\circ} \mathrm{C}$. The organic residue remained even above $500^{\circ} \mathrm{C}$ under nitrogen atmosphere, whereas no residue was found in air at the same temperature.

\section{Dynamic Viscoelasticity}

Figure 3 shows the temperature dependence of the mechanical loss tangent, tan $\delta$, of PSHD (Sample: Table I, No. 1 and No. 5) measured at $110 \mathrm{~Hz}$. There was no peak from -160 to $+100^{\circ} \mathrm{C}$. The peaks were observed at $133^{\circ} \mathrm{C}$ ( $\beta$ peak), $246^{\circ} \mathrm{C}$ ( $\alpha$ peak), and $335^{\circ} \mathrm{C}$ (decomposition peak). The PSHD sample with a higher 1,4-unit content ( $84 \%$, Sample No. 5) gave a 


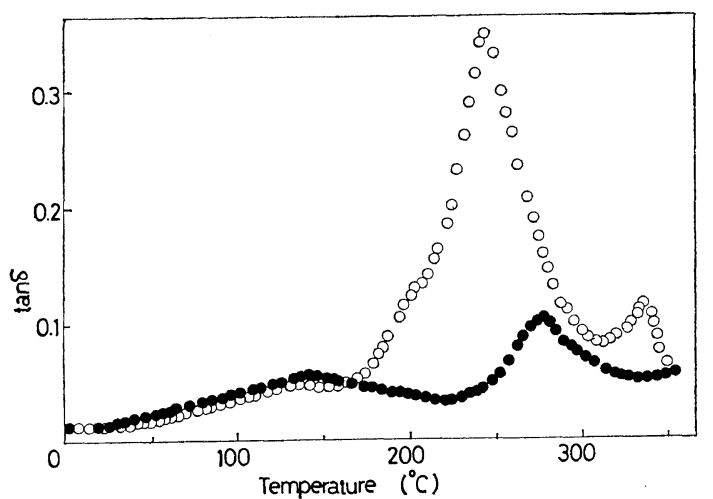

Figure 3. Tan $\delta$ vs. temperature for PSHD samples: (O) $42.2 \%$ of the 1,4-units (sample, No. 1); $84.3 \%$ of the 1,4-units (sample, No. 5).

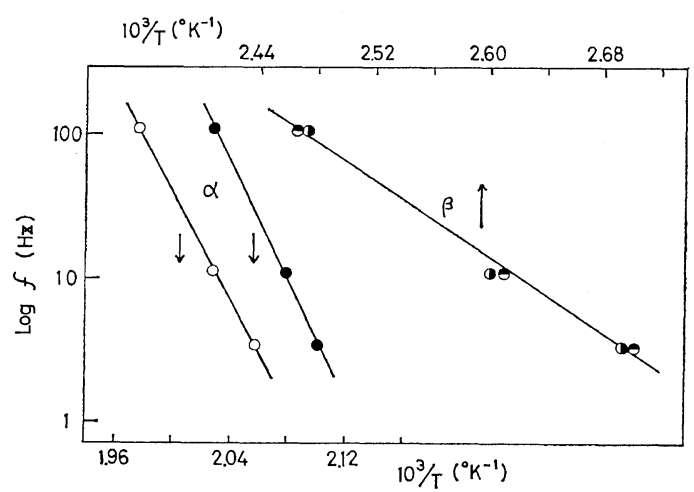

Figure 4. Transition map of $\alpha$ and $\beta$ dispersions $\left(\log f_{\max } v s 1 / T\right)$ : Sample, No. $2(O, O) ;$ No. 3 $(\bigcirc, \Theta)$.

smaller $\tan \delta$ value above $170^{\circ} \mathrm{C}$, and the $\alpha$ peak shifted to the higher temperature side when compared with the sample with lower 1,4-unit content (42\%, sample No. 1). This difference may be explained by assuming that the sequence of the 1,4-unit is more rigid than that of the 1,2unit and that the increase in the former unit suppresses the motion of molecular chains to a large extent. It is suspected that the stiffness of the PSHD molecule is mainly governed by the 1,4-structure.

Figure 4 shows the transition map of the $\alpha$ and $\beta$ peaks, which was prepared by changing the measuring frequency. The mean activation energy of the $\alpha$ peak is $86 \mathrm{kcal} / \mathrm{mol}$ and that of the $\beta$ peak is $30 \mathrm{kcal} / \mathrm{mol}$ for both samples.
First the value of activation energy of the $\alpha$ peak is estimated based on the WLF equation, which has been shown to be widely applicable to the glass-forming flexible molecules. The WLF equation is given by ${ }^{6}$

$$
\log a_{T}=-c_{1} \mathrm{~g}\left(T-T_{\mathrm{g}}\right) /\left(c_{2}{ }^{\mathrm{g}}+T-T_{\mathrm{g}}\right)
$$

where $a_{T}$ is the shift factor when $T_{\mathrm{g}}$ is taken as the reference temperature and $c_{1}{ }^{\mathrm{g}}$ and $c_{2}{ }^{\mathrm{g}}$ are constants characteristic of the polymer species. In the conventional expression, $c_{1} \mathrm{~g}=17.44$ and $c_{2}{ }^{\mathrm{g}}=51.6$ are employed as the general values applicable to all kinds of polymers forming glassy states.

The activation energy for relaxation at any temperature $T$ above $T_{\mathrm{g}}, \Delta H_{\mathrm{a}}$, is evaluated by differentiating eq 3 with respect to the reciprocal temperature as follows:

$$
\Delta H_{\mathrm{a}}=2.303 R c_{1}{ }^{\mathrm{g}} C_{2} \mathrm{~g} T^{2} /\left(c_{2} \mathrm{~g}+T-T_{\mathrm{g}}\right)^{2}
$$

If we assume that $T_{\mathrm{g}}$ of PSHD corresponds to the temperature at which the $\tan \delta$ curve deviates from the background, $\Delta H_{\mathrm{a}}$ of the $\alpha$ peak at its peak temperature is evaluated by eq 4 . The method for determining $T_{\mathrm{g}}$ was described first by Hideshima et al., ${ }^{7}$ and is conveniently used for PSHD samples with various copolymer compositions. Its principle is based on the assumption that the beginning of any thermal motion associated with the micro-Brownian movement is reflected in the rise of the $\tan \delta$ curve of the $\alpha$ peak. For example, the $\alpha$ peak temperature and the $T_{\mathrm{g}}$ value are read from the $\tan \delta$ curve of Sample No. 5 in Figure 3 as $270^{\circ} \mathrm{C}$ and $200^{\circ} \mathrm{C}$, respectively. Substitution of these values into eq 4. results in $\Delta H_{\mathrm{a}}\left(250^{\circ} \mathrm{C}\right)=70 \mathrm{kcal} / \mathrm{mol}$. This value is smaller than the observed value of $86 \mathrm{kcal} / \mathrm{mol}$ but not inconceivable according to the WLF equation, especially when $T_{\mathrm{g}}$ is determined by the above method.

The basic assumption of the WLF equation is that the increase in the free volume fraction and the conformational change of the main chain take place by thermal activation. In the case of the PSHD chain, however, such conformational change is difficult to assume, as far as space-filling model can suggest.

Another possible interpretation of the molecular process of the $\alpha$ peak is the torsional oscillatory motion around the molecular axis. Such 


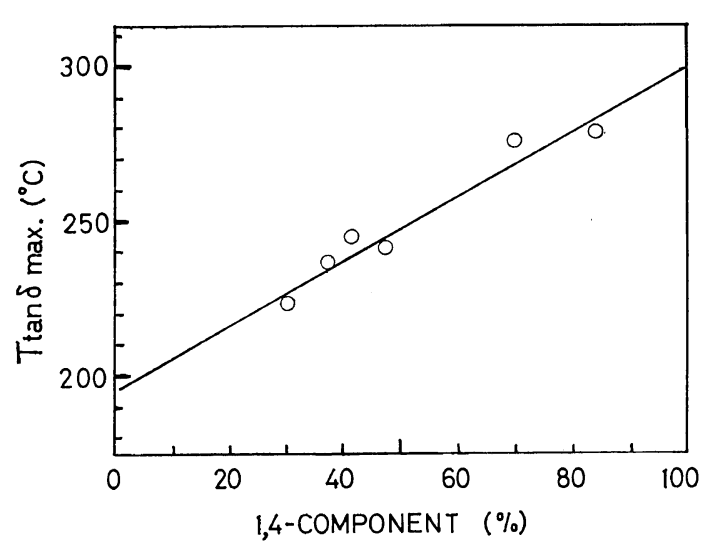

Figure 5. Temperature for $\tan \delta$ maximum (110 $\mathrm{Hz})$ s. fraction of the 1,4-unit.

a mechanism was assigned by Yamafuji, et al.. ${ }^{8}$ to the $\beta$ relaxation of the polymers having no side chains such as poly(vinyl chloride), poly(ethylene terephthalate), etc. There will be various modes of the oscillatory motion around the chain axis. The lower modes of motion are considered to be influential along some lengths of the main chain which include several monomeric units. In other words, the $\alpha$ peak temperature and its relaxation magnitude are affected by the copolymer composition. This expectation is supported by the results in Figure 5 .

Figure 5 shows the relationship between the $\alpha$ peak temperature in the $\tan \delta$ curve and the fraction of the 1,4-units in the polymer. The linear relation determined by the least squares method is given by eq 5 :

$$
T_{\text {tan } \delta, \max }\left({ }^{\circ} \mathrm{C}\right)=1.03 F+197
$$

where $F$ denotes the percent fraction of the 1,4-units. Using this equation, the temperature of the $\tan \delta$ peak for PSHD with $100 \%$ 1,4-units is evaluated as $300^{\circ} \mathrm{C}$ for the $\alpha$ peak. The polymer with $100 \%$ 1,4-units might crystallize and become more heat-resistant. The decrease in the intensity of the $\alpha$-peak at higher 1,4-unit contents, as seen in Figure 3, will also produce better heat resistance.

The activation energy of the $\beta$ peak $(30 \mathrm{kcal} /$ mol) is higher than those of the subpeaks of the usual vinyl polymers $(10-20 \mathrm{kcal} / \mathrm{mol}){ }^{9}$ This difference is not unreasonable when it is taken into account that the $\beta$ peak temperature of PSHD is located at a temperature higher than those of other polymers. On the other hand, the nature of the $\beta$ peak seems to be attributable to the local relaxation mode of the main chain associated with sequence shorter than that associated with the $\alpha$ peak. A more definite conclusion can only be presented after detailed studies on the stereoisomerism are performed. At present the following facts are available for discussing the nature of the $\beta$ peak.

As seen in the thermomechanical curves of Figure 3, the $\beta$ peak temperature and its relaxation magnitude are not sensitive to the copolymer composition or the difference in the mainchain configuration. When the sample was exposed to benzene vapor, there was no change in the magnitude of the $\beta$ peak. Therefore, this peak is conceivably governed by the intramolecular factor. Soaking of the sample in sulfuric acid produced crosslinking, but the $\beta$ peak was observed at almost the same temperature. This suggests that the molecular motion associated with the $\beta$ peak is confined within a very limited range of the molecule.

The PSHD film (No. 1) turned bright black, probably due to development of the conjugated olefin system, when it was subjected to heat treatment up to $360^{\circ} \mathrm{C}$. The $\alpha$ and $\beta$ peaks disappeared almost completely after the heat treatment.

Figure 6 shows the storage modulus $\left(E^{\prime}\right)$ curve and the loss modulus $\left(E^{\prime \prime}\right)$ curve for PSHD

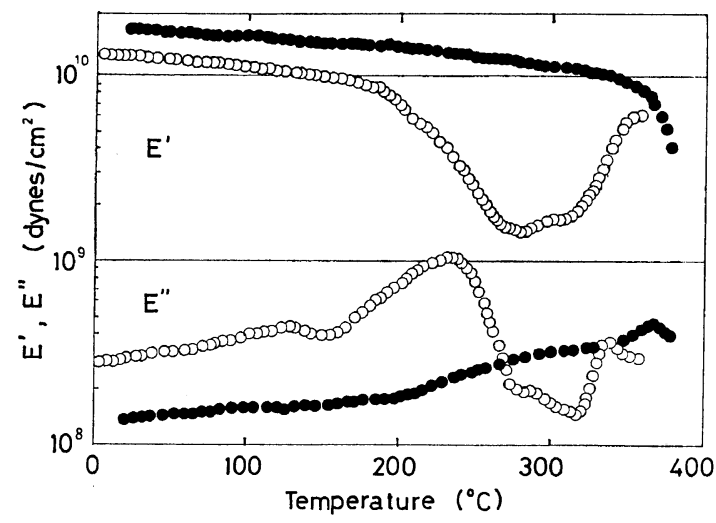

Figure 6. Temperature dependence of $E^{\prime}$ and $E^{\prime \prime}$ after heat treatment up to $360^{\circ} \mathrm{C}(O)$ and for the original sample $(\mathrm{O})$. 
samples before and after the heat treatment. The storage modulus varied little above $300^{\circ} \mathrm{C}$ for the heat-treated sample. This means that the thermal oxidation and intermolecular crosslinking inhibit every molecular motion. Consequently, a peak at $335^{\circ} \mathrm{C}$ in the $\tan \delta$-temperature curve of the original sample is assigned to the initiation of such a crosslinking reaction. This temperature corresponds to the peak located at $350^{\circ} \mathrm{C}$ in the DSC curve. The progress of the crosslinking reaction was reflected in the rise of the modulus curve above $300^{\circ} \mathrm{C}$, as seen in Figure 6.

\section{REFERENCES}

1. O. Ohara, C. Aso, and T. Kunitake, J. Polym. Sci., 11, 1917 (1973).

2. T. Kunitake, T. Ochiai, and O. Ohara, J. Polym. Sci., Polym. Chem. Ed., 13, 2581 (1975).
3. O. Ohara, C. Aso, and T. Kunitake, Nippon Kagaku Kaishi (J. Chem. Soc. Jpn., Chem. Ind. Chem.), 1973602.

4. M. Kurata, M. Iwata, and K. Kameda, in "Polymer Handbook," Vol. IV-1, J. Brandrup and E. H. Immergut, Ed., Interscience Publishers, Inc., New York, N. Y., 1965.

5. K. Alder, H. J. Ache, and F. H. Flock, Chem. Ber., 93, 1888 (1960).

6. J. D. Ferry, "Viscoelastic Properties of Polymers," John Wiley \& Sons, Inc., New York, N. Y., 1960.

7. N. Saito, K. Okano, S. Iwayanagi, and T. Hideshima, "Molecular Motion in Solid State Polymers," Solid State Physics, Vol. 14, Academic Press, New York, N.Y., 1963, p 494.

8. K. Yamafuji and Y. Ishida, Kolloid-Z. $Z$. Polym., 183, 15 (1962).

9. N. G. McCrum, B. E. Read, and G. Williams, "Anelastic and Dielectric Effects in Polymeric Solids," John Wiley \& Sons, Inc., London, 1967. 